\title{
An Analysis of the Trend of Cross-Straits Cold Chain Logistics Development
}

\author{
Tien-Chin Wang, Chi-Fa Ho*
}

Dept. of International Business, National Kaohsiung University of Applied Sciences, Kaohsiung, Taiwan

Email address:

tcwang@kuas.edu.tw (Tien-Chin Wang),ho.chifa@msa.hinet.net (Chi-Fa Ho)

${ }^{*}$ Corresponding author

\section{To cite this article:}

Tien-Chin Wang, Chi-Fa Ho. An Analysis of the Trend of Cross-Straits Cold Chain Logistics Development. Science Innovation. Vol. 4, No. 6, 2016, pp. 290-295. doi: 10.11648/j.si.20160406.18

Received: November 17, 2016; Accepted: December 7, 2016; Published: December 30, 2016

\begin{abstract}
The cooperation in cold chain logistics across the straits has its origin in the "Cross-Straits Economic Cooperation Committee" for the Economic Cooperation Framework Arrangement (ECFA) established in 2011. Under the arrangement, Tianjin and Xiamen in China will be the two demonstration cities for pilot running of cross-straits cold chain logistics. In Taiwan, the Ministry of Economic Affairs will orchestrate the program and integrated with the industry in the formation of the "Cross-Straits Cold Chain Logistics Technology and Service Federation" with a view to combining the momentum of the industry and the formation of an alliance to launch for collective deployment. This has been a success in matching the enterprises and organizations in cold chain across the straits with the signing of more than $39 \mathrm{MOU}$ or contracts, and brought about new business opportunities for the industry and logistics service sector of Taiwan with the result of NT\$1.76 billion worth of investment and purchase. In China, effort has been made lately in regulating and standardizing cold chain food. The cold chain business in Taiwan must fully under the rules and standard of international operation so as to get the grip of the opportunity of internationalization and develop global competitive power. Taiwan is at an ideal location in Asia-Pacific and the logistics business has been well-developed with advanced technology and supply chain management service. With ECFA as an advantage, industry chain integration and optimization of operation efficiency could be accomplished through the development of system platform and standardization for the joint inspection across the straits in information sharing, and the establishment of the system for joint packaging, and storage standards under a set of uniform rules. The cold chain industry structure could also be developed into a global business chain more efficiently so that Taiwan could be the base in Asia Pacific for value adding the extent to which the cold chain logistics industry in Taiwan could extend all over Asia and even the whole world.
\end{abstract}

Keywords: Cold Chain Logistics, Frozen Food, Storage and Transport, Industry Clustering, Technology Integration

\section{兩岸冷鏈物流發展趨勢分析}

\section{王天津，何基發*}

高雄應用科技大學國企系, 高雄市, 台灣

邮箱

tcwang@kuas. edu. tw（王天津）, ho. chifa@msa. hinet.net（何基發）

摘要：兩岸冷鏈物流產業的合作，源於2011年成立ECFA「兩岸經濟合作委員會」，並選定大陸天津、廈門為兩岸冷鏈 物流試點合作的示範城市, 台灣方面則是由經濟部扮演支援推手, 並整合業者成立「兩岸冷鏈物流技術與服務聯盟」, 希透過結合產業能量、建立聯盟平台, 來推動群聚佈局。也成功媒合兩岸冷鏈企業及組織, 累計簽訂39份合作意向書 或合約, 帶動台灣產業與物流服務業新商機, 並促成投資與採購約 17.6 億元。近來大陸亦大幅邁進，針對冷鏈食品的 規範、標準迫切施力。台灣冷鏈業者經必須充份瞭解國際運作的規範與遵循標準, 掌握國際化契機及全球化競爭力。 
台灣擁有位於亞太區域中心的優越地理位置, 及台灣物流業成熟領先的技術與供應鏈管理服務, 加上兩岸簽署ECFA的 利基, 若能發展系統平台與標準制定, 打造出兩岸聯檢資訊共用平台, 以及共同制定包裝、儲存標準及統一規範, 推 動產業升級及創新, 達到產業鍕整合及效率的最大化。亦能將冷鏈產業建構成更效率化的全球商業鏈, 打造台灣成為 產業亞太加值基地，使台灣冷鏈物流業運籌亞洲、布局全球。

关键词：冷鏈物流，冷凍食品，貯藏運輸，產業群聚，科技整合

\section{1. 引言}

冷鏈物流已為世界各國相繼的推動產業，對冷鏈物 流業的重視度也愈趨強烈, 澳州、德國、比利時、新加 坡等均有相關組織成立 (CCA-Cool Chain Association; CCCCold Chain Center; Spring Cold Chain Center), 且已有CCQI冷鏈品質指標準則試行推動; 近來大陸也大 幅邁進, 對於冷鏈食品的規範及標準均迫切施力。面對 國際冷鏈環境與活動蓬勃發展之趨勢, 冷鏈活動之重要 性已凌駕國際界限之上, 歐洲（歐盟）對進口食品控管 愈趨嚴格, 尤其低溫、生鮮食品的進口標準更積極在研 擬中, 國際運送品質愈形受到重視。冷鏈產業必須透過 提升服務大範圍區域的低溫運輸能量, 進行產業革命性 維新以確實掌握低成本、高品質、低風險等關鍵因素, 前進全球物流服務市場。

對於國際冷鏈之推動趨勢與國際規範, 台灣應要多 所掌握, 而且發揮引以為傲的管理優勢才能更勝一籌。

冷鏈物流業者除確認規範、準則及人才培訓之必要性之 外, 也需推動共識, 建構台灣Cold Chain Center之推動 策略, 並且持續掌握國際冷鏈推動情勢的管道, 支援台 灣冷鏈物流業獲取更多跨國服務商機。兩岸產業佈局, 初步以天津、廈門兩城市作為優先試點示範城市。台灣 冷鏈相關廠商若能整合成功推出完整解決方案, 冷鏈物 流將會是台灣廠商進軍中國大陸物聯網應用的近程戰略 目標。

本研究以兩岸低溫物流合作策略: (1) 完善企業試點, 促成兩岸企業合作共贏; (2) 成功於試點城市合作物流園 區, 活化物流據點; (3) 推動兩岸食品流通綠色通道, 進 行分析。提供兩岸冷鏈物流的市場相關分析, 市場概要 和結構、市場規模趨勢, 推動、阻礙市場要素與其影響 力, 作為冷鏈物流業者市場商機與發展之評估、決策。

\section{2. 冷鏈物流的定義}

冷鏈物流 (Cold Chain Logistics) 泛指冷藏冷凍類 食品、生技藥品、電子物品等從生產、蓄冷、儲藏、運 輸、銷售，到消費者之過程，提供專業技術使其全程處 於恆定低溫狀態, 有效結合低溫環境下的硬體設備, 確 保貨物最佳質量之控管決策方案及專門的冷鏈物流網路 和供應鏈體系。

\section{1. 國際冷鏈推動組織}

(1) 歐洲Cool Chain Association (CCA)
CCA是一個非營利組織, 成立於 2003 年, 其目的是減 少浪費, 協調全球運作促進和實現垂直和横向協作, 處 理易腐壞、需要溫度控制儲存和配送的食品、花卉、藥 品及醫療保健及科技產品之協會, 以造福於消費者及供 應鏈的參與者。因而建立共通程序、建立教育培訓及創 新模式及組織成員之間連繫的標準、建立共通的測量標 準。CCA冷鏈協會以 (1) Get Cooler：維持產品品質與生 命; (2) Get Cheaper : 零售成本需被聚焦檢討; (3) Get Faster：可靠度與速度須被改善; (4) Get Closer：瞭解 最終客戶，四項訴求做為會會員共同追求之目標與願景。 並以CCQI (Cool Chain Quality Indicators) 冷鏈品質指 標作為CCA協會成員之共同遵循規範, 並致力推廣將無線 射頻識別技術 (RFID) 運用於監控貨物上。

(2) 澳洲Cold Chain Center (CCC)

澳洲Cold Chain Center其組成的目的是以提高南澳 大利亞州和澳大利亞的出口冷鏈物流之整合性組織, 其 目標在加強海外市場的出口競爭力。提供全球冷鏈連接 服務, 協助冷鏈物流運作訓練、建立每個鏈結之績效標 準、進行冷鏈物流鑑定、進行標竿管理、研究冷鏈創新 解決方案、提供運輸及物流服務資訊、進行冷鏈診斷 （監視一時間、溫度、地點, 檢討, 分析）, 提供平台連 結全球客戶及會員建立合作關係。

\section{2. 國際冷鏈物流發展概況}

目前全球冷鏈市場以歐美及日本發展較為完善, 美 國市場, 約有 $90 \%$ 的低溫食品運送符合冷鏈的定義要求, 美國的冷鏈物流已經相當普及, 美國低溫食品在加工運 輸環節中的損耗率僅為 $1 \%-2 \%$, 不僅能保障費者的食品安 全, 對業者的耗損成本也大幅降低, 提高經濟效益。拿 大是冷鏈物流體系完善的國家, 其生鮮低溫農產品的銷 售，占全國商品銷售值 $50 \%$ 左右。歐洲部有 $50 \%$ 的低溫食 品符合冷鏈要求。日本農林水產省成立了食品低溫流通 推進協議會，依循低溫管理食品的品質管理方法及低溫 流通設施完善方向, 制定食品低溫流通溫度範圍, 使生 鮮食品冷鏈保鮮技術進入了基本完善的階段。

聯合國預估，2030年全球都會人口將達到約36億人， 高達全球人口總數的 $60 \%$, 而都市生活步調較為緊湊, 在 飲食上講求簡單便捷, 因此可望帶來冷凍食品需求提升。 但隨著消費者對於食品品質要求的提高, 使得冷凍食品 業者不斷開發各式各樣的料理以搶攻商機。依據市調機 構Frost\&Sullivan調查, 印度冷凍食品產業2013年市值 美金2.5億元, 每年約有 $15 \%$ 至 $20 \%$ 的成長幅度, 此數據也 在在說明了全球冷凍食品市場的龐大商機。 
中國大陸雖然其低溫食品目前約只有30\%的低溫食品 採用冷鏈運輸, 佔總體食品比率不高, 其冷鏈流通率卻 不及 $20 \%$ 。據空調製冷大市場調查瞭解，歐美、日本等發 達國家農產品進入冷鏈系統流通的在 $90 \%$ 以上, 其中水果 冷鏈流通率高達 $95 \%$ 以。台灣目前進入冷鏈系統的蔬菜 類比重只占到全部蔬菜的 $5 \%$, 肉類只占到 $15 \%$, 水產品也 只有 $23 \%$ 。

\section{3. 兩岸冷鏈物流發展概況}

在落實「開啟兩岸經貿協商新時代」及「深耕台灣、 全球連結」的施政理念, 台灣冷鏈聯盟以關鍵技術研發、 實務經驗合作與豐富物流領域知識, 構建具多溫層、少 量、多樣等特色之全程溯源保鮮服務解決方案與創新服 務模式, 透過兩岸合作機制, 以天津與廈門作為第一階 段的兩岸冷鏈物流試點城市, 按照「合作規劃」、「合 作建置」、「合作營運」三階段推進, 建立國內產業邁 向規模化與品牌化的機會。歷經多次磨合, 兩岸逐步訂 出未來冷鏈物流的合作發展策略, 短中期先結合台灣過 去二十多年於冷鏈物流上所累積的軟實力 (台灣精神/關 鍵智財與技術/運籌人才與系統/管理品質)，依據大陸所 設定的冷鏈市場發展目標引入人才、技術、經驗, 㣣物 流與商流實力與大陸合作，善用其環境優勢 (市場、資源、 土地、資金、低成本生產)，共同提升與布局大陸冷鏈物 流市場。長期則朝建立具國際競爭力之冷鏈服務品牌推 進, 透過品牌的延伸與規模的厚植, 進而佈局全球。

\section{1. 台灣冷鏈物流發展概況}

台灣近年來低溫食品市場快速發展, 產生了大量的 低溫物流需求, 亦培飬出台灣低溫物流服務的實力。近 五年台灣冷凍食品 (含冷凍肉類、冷凍水產食品、冷凍蔬 菜果實、冷凍調理食品等) 銷售值來觀察, 除2014年出現 小幅衰退外, 其他年度銷售表現均維持成長態勢, 顯示 此產業仍穩定向上發展當中。如 (圖1)

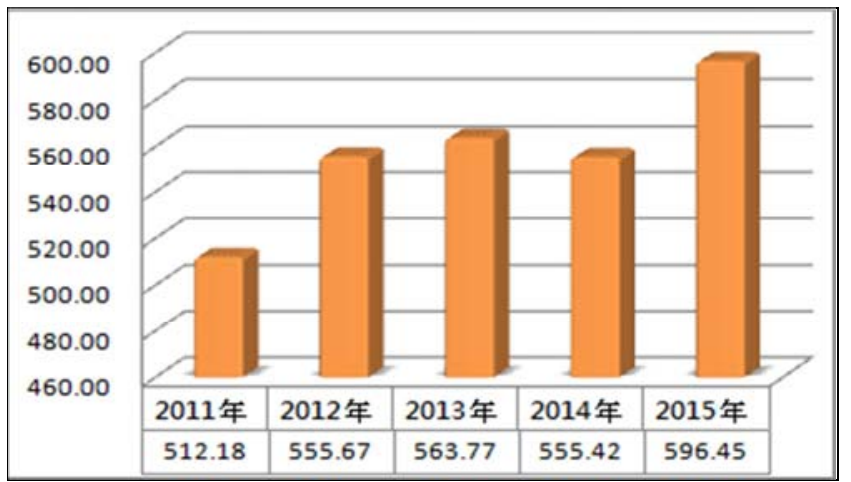

資料來源：台灣經濟部統計處；本研究整理 (單位: 新台幣億元)

圖1 2011年 2015年台灣冷凍食品銷售額。

隨著民生消費能力與型態的轉變，根據相關數據統 計：2015年台灣冷藏車增長 14000 輛左右, 冷藏車保有量 突破9萬輛, 同比增長18.4\%; 冷庫新增390萬噸, 冷庫總 保有量達到 3710 萬噸, 摺合 9275 萬立方米, 同比增長
$11.76 \%$; 果蔬、肉類、水產品的冷鏈流通率分別達到 $22 \%$ 、 $34 \% 、 41 \%$ ，冷藏運輸率分別為 $35 \%$ 、 $57 \%$ 、 $69 \%$ 。預計到 2020年台灣冷鏈市場將達到3479億規模, 複合增長率為 17. $1 \%$ 。

隨著民生消費能力與型態的轉變, 台灣在低溫食品 市場的發展上有著顯著的進步，不僅在系統管理與科技 應用發展完備, 同時也累積了完整且豐富的服務經驗。 就技術面而言, 不論是單一技術 (包含蓄冷保溫模組、多 溫層蓄冷片、溫度監視器、RFID辨識系統、資通訊管理 系統等) 或是整合性技術 (節能、自動化冷鏈物流中心, 科技整合加值之創新營運模式, 全程即時載途與溫度追 蹤監控模式等)。冷鏈物流產業經過多年的發展與整合, 專業分工架構也已成型且趨於完善, 從倉儲、配送、資 訊服務、設備研發、銷售通路等各業種、業態均表現亮 眼。但是礙於台灣內需市場規模過小之瓶頸, 因此, 唯 有透過資本、人才、技術等資源的整合，方能促進冷鏈 物流服務的質變與進化, 加速台灣物流經驗與知識的經 濟化和資本化。

在民眾消費型態及消費能力的改變，台灣在政府與 民間冷練物流業者的努力與經營, 在低溫冷凍食品市場 不斷的開發創新, 技術及保存上有顯著提升與進步, 冷 鍊系統管理與科技應用合併發展完備, 也具備了完整豐 富的服務經驗。經由台灣政府的輔導與整合冷練業者之 轉型, 台灣的冷鍕產業發展成功因素可歸類為: (1) 政府 積極推動; (2) 連鎖體系帶動; (3) 專業分工需求; (4) 流 通型態變革; (5) 低溫食品普及; (6) 科技有效應用。

（1）政府積極推動：在政府整體推動規劃中，冷鏈物 流推動目標包括：1. 持續追蹤先進國家之推動狀 況, 並彙集國際相關規範與準則; 2. 規劃冷鏈推 動組織之成立方式，研擬組織目標與運作機能; 3 . 規劃台灣冷鏈業運作標準之建立程序; 4. 建議冷 鏈專業人才之培育方式; 5 . 配合取消私宰政策研 擬物流建議對策。有系統的規劃來引導業者自我 要求與產業水準的提升, 帶領建立國內冷鏈產業 的推動基磐，成立一共同組織研擬冷鏈供應鏈各 階段的驗收標準與條件, 建立GMP、CAS標準程序 與作業規範, 以協助業者掌握國際化契機及全球 化競爭力。此外, 低溫設施的規劃佈建與低溫環 境的維護控管, 皆需要有專業的人才及Know-how, 才能建立有效率的動線及有品質的環境, 推動冷 鏈體系 (Cold Chain) 使得食品的產、儲、運、銷、 配、用, 每一環節都能保持適當的溫度, 以確保 食品品質和衛生。再透過人才培訓與知識廣宣帶 動國內業者對冷鏈的重視度。同時結合產、官、 學、研各界的力量, 推動成立冷鏈產業服務網, 長期聘顧專家、學者收集研究國際各國的相關資 訊, 並針對低溫供應鏈各階段的活動制定符合產 業需求之因而未來的推動中將聘請具專業冷鏈能 力或通過認證的專家來協助, 建立評析服務、諮 詢診斷的管道。結合國內學界與研界之研發專家 持續努力, 積極推動兩岸物流發展。 
（2）連鎖體系帶動：連鎖商店與餐廳積極強化連鎖體 系多由總公司統籌, 使用相同食品物流管理規範 的營運管理系統; 低溫保存的商品, 需仰賴分散 物流的作法, 因此綿密物流服務網極為必要。台 灣便利商店一日四配、低溫一日兩配需求, 已經 發展出超強物流系統。

（3）專業分工需求: 製造、消費與物流分工在原物料 生產過程中, 包括上上游、上游、上中游、中游、 下游，製造、消費與物流進行分工合作。

（4）流通型態變革: 冷鏈物流中心營運、少量多樣流 通型態興起物流網路更加單純化; 專業分工, 以 提升企業資金運轉效能, 分攤營運風險; 集中處 理, 可以提高冷鏈物流作業效率, 減少店面收貨 次數; 形成經濟規模可滿足少量多樣高頻的配送 需求與設備投資。

（5）低溫食品普及：低溫食品占比提升至35\%低溫食品 管理原則是原料驗收後進行前處理、加工調理、 急速冷凍、包裝、自主核對總和裝箱, 最後通過 TTT (Time-Temperature-Tolerance)，即低溫貯 存、低溫配送、低溫陳售。如今, 低溫食品占比 提升至 $35 \%$ 。

（6）科技有效應用: 資通訊、冷凍、辨識等技術的發 展與應用在冷鏈物流品質管理方面, 技術應用主 要涉及全溫層物流中心、箱溫、車溫、門市驗收; 在冷鏈物流系統管理方面, 主要包括決策支援管 理平臺、跨國履歷追蹤管理、運輸全程監控管理、 冷鏈物流規範與標準等。

\section{2. 大陸冷鏈物流發展概況}

大陸消費者的購買力逐年上升，對優質冷凍產品需 求亦不斷增加, 特別是中產或以上階層對高端進口食品, 包括凍肉、海產、蔬果、乳製品、紅酒和其他生鮮食品, 以及各類進口的健康食品趨之若䳱, 加上內地急速的城 鎮化步伐, 不少城市的物流配送系統近年快速發展, 使 企業可以利用日漸發展成熟的冷鏈物流服務引進有關產 品, 以滿足蓬勃的市場需求。當前, 「一帶一路」中國 戰略的實施, 上海、廣東、天津、福建自貿區的發力, 中澳、中韓等貿易協定的簽署，使得跨境冷鏈業務日益 頻繁, 而移動網際網路的崛起, 又催生了生鮮電商、冷 鏈宅配的興起, 都將給中國冷鏈物流行業的發展提供廣 闊的空間和巨大的市場份額。雖具如此大的消費潛力, 其食品冷鏈流通率卻不足 $20 \%$, 且糹鏈狀況頻繁, 導致因 商品失溫而損失的金額每年高達新台幣 5,000 億元。目前 中國大陸在冷鏈物流上缺乏整體解決方案, 相關技術仍 處於起步階段, 相關的冷鏈基礎設施亦嚴重不足, 冷鏈 技術、法規和標準尚不健全, 無法滿足產業需求。此外, 偏低的冷鏈使用率使得商流無法帶動物流, 連帶使得第 三方物流發展滯後。

為促進農產品冷鏈物流的發展, 中國大陸發改委已 提出《農產品冷鏈物流發展規劃》, 對於肉食和水產品 的冷鏈物流水準須大幅提升, 蔬菜和水果、肉類、水產 品冷鏈流通率分別由目前的 $5 \%$ 、15\%、23\%左右提高到 $20 \%$ 、
$30 \% 、 36 \%$ 以上; 冷鏈運輸率分別由目前的 $15 \%$ 、30\%、 $40 \%$ 左右提高到 $30 \%$ 、50\%、65\%左右; 流通中產品腐損率分別 由目前的 $20 \% \sim 30 \% 、 12 \%$ 、 $15 \%$ 左右下降至 $15 \%$ 、 $8 \%$ 、10\%以 下。同時, 預備培育500家冷鏈物流核心企業, 建置功能 完善與先進的全國農產品冷鏈物流體系框架, 加快建設” 從田間到餐桌”的一體化冷鏈物流體系與高效、創新的 跨區域冷鏈物流配送中心。

由此可見, 冷鍕物流已成為中國大陸「十二五規劃」 的重點產業, 大陸方面正提供大量資源廣邀國際大廠進 駐, 台灣在此方面具有堅強技術能量與人才, 實應藉此 機會透過槓桿操作, 進行國際布局。

\section{4. 兩岸冷鏈物流合作策略}

兩岸冷鏈物流技術與服務支聯盟推動成立係以促進 兩岸冷鏈商品流通與物流發展為宗旨。其發展目標為: 整合業界資源聯合行銷、建立兩岸冷鏈物流標準、促進 兩岸冷鏈貿易及投資、提升兩岸冷鏈技術與人才。為落 實馬總統「開啟兩岸經貿協商新時代」及「深耕台灣、 全球連結」的施政理念。

\section{1. 兩岸冷鏈物流產業合作狀況}

（1）分享大陸內需市場：兩岸於2008年11月正式啟動 「搭橋專案」, 促成兩岸冷練物流業者合作共同 拓展並分享中國大陸內需市場商機, 藉此提升國 際競爭力。

（2）建立兩岸合作試點產業：2011年2月成立「兩岸產 業合作策略小組」, 選定食品與精準物流為兩岸 合作試點產業, 協助台灣業者搶攻大陸「十二五」 商機。

（3）積極促進兩岸冷鏈物流合作：為了協助台灣冷鏈 業者突破在大陸之經營瓶頸, 並有效促進兩岸低 溫商品流通與物流產業的發展, 兩岸業者於 2011 年11月4日成立「兩岸冷鏈物流技術與服務聯盟」, 目前已有141家業者參與, 並以發展產業群聚合作 模式, 爭取商機與獲利; 制定兩岸冷鍕物流運作 標準，建立認證機制; 研發冷鍕物流技術, 培育 專才，布局智慧財; 健全兩岸冷鏈物流平等互惠 之產業發展環境等運作策略, 集結團隊參與兩岸 試點計畫。

（4）訂定兩岸共通產業標準與品管規範：2012年兩岸 共同簽署15份合作意向書與契約, 雖兩岸冷鏈業 者已積極進入具體落實階段, 但現階段仍面臨著 兩岸物流運作標準不一、通關/檢驗/檢疫問題尚 未解決、台商物流運輸執照不易取得, 及大陸國 營企業招標限制等瓶頸。為了解決這些瓶頸障礙, 且更快速地推動兩岸冷鍕物流合作，未來更應盡 快依據ECFA精神與框架, 建立G2G合作平台以推動 兩岸重大經合項目，並訂定兩岸共通產業標準與 品管規範, 以及爭取物流用地與優惠政策/措施。

（5）確定年度產業合作目標：2013年將以透過試點引 導城市物流革新、結合技術提升物流服務能力、 
合作布局活絡兩岸實質商貿、持續媒合增進兩岸 產業合作等四方向作為年度產業合作目標。

\section{2. 兩岸低溫物流合作策略}

（1）完善企業試點，促成兩岸企業合作共贏：規劃並 落實於27項具體方案 (天津20項、廈門7項)，逐步 整合跨岸產業鏈、天津產業鏈、廈門產業鏈。促 成兩岸成功合作案例, 促進台商參與當地服務, 促成雙向投資與採購，保障食品安全及民生物流 配套促進消費，建立產業標準和規範，提升冷鏈 物流管理。經過近5年的推動, 冷鏈物流合作已在 總體規劃、標準合作、港區合作、商貿合作、技 術合作、合資合營等層面取得不錯成果，建置節 能、高效多溫層冷庫改善產業運作環境_引入食品 加工創新技術創造產品價值, 強化物流集散機能 提升競爭力建立不斷鏈物流體系保障食品安全, 建立民生物流配套促進消費。促成兩岸冷鏈物流 合作發展策略, 以台灣營運與技術優勢結合大陸 資源與市場共創雙贏。

（2）成功於試點城市合作物流園區，活化物流據點: 配合ECFA兩岸重大經合項目, 建構產業發展優勢 環境; 聚焦二模式促成產業群聚效益規劃, 籌組 兩岸冷鏈物流技術與服務聯盟, 從市場面、營運 面、技術面切入, 確認優先試點運作模式, 持續 發展系統整合 total solution; 並進行兩岸對接, 引導兩岸業者之媒合商機, 成功發展產業群聚合 作模式, 爭取商機與獲利; 制定兩岸冷鏈物流運 作標準, 建立認證機制; 研發冷鏈物流技術, 培 育專才, 布局智慧財; 健全兩岸冷鏈物流平等互 惠之產業發展環境等運作策略。逐步整合跨岸產 業鏈、天津產業鏈、廈門產業建置節能、高效多 溫層冷庫改善產業運作環境並引入食品加工創新 技術創造產品價值鏈, 強化物流集散機能提升競 爭力。以台灣營運與技術優勢結合大陸資源與市 場共同創造冷鏈加值與價值服務, 共同爭取冷鏈 服務市場。

（3）推動兩岸食品流通綠色通道: 鑑於生鮮農產品生 性容易腐敗不易儲藏影響到出口業務推動, 因此 若能在確保農產品食用安全的前提下, 透過綠色 通道來強化農產供應鏈整合, 縮短通關時間, 減 少繁瑣的通關檢驗流程, 不僅可以確保農產品的 美味品質提高市場接受度, 還有助於透過電子商 務來推動農產業務（如以農產品網路銷售為主的 淘寶、天貓、中國特色館等) 若能全面實施綠色 通道確實有助於台灣生鮮農產品在中國市場的銷 售與布局。促成台商地方性優惠政策與措施, 包 含尋地與爭取地稅優惠、建立特區對特區綠色通 道, 降低商物流業者兩岸對接門檻。以ECFA對接 機制優先解決法規與標準, 包含解決報關檢疫問 題、重視認證及生產履歷, 並提供個案協助。兩 岸商品流通與跨岸保鮮、兩岸合作落實報關報檢 便捷化、兩岸共同突破貿易與物流瓶頸、加速台
灣農特產品行銷大陸機會。堆動兩岸冷鏈物流合 作在總體規劃、標準合作、港區合作、商貿合作、 技術合作、合資合營藉由兩岸冷鏈物流的試點合 作, 集結國內加工食品、冷凍食品與農產品, 兩 岸食品物流服務與擴展、低溫共配與城際合作創 新運輸服務模式、海運快彪支援兩岸商品流通、 兩岸合資拓展中國大陸北方冷鏈物流市場、冷凍 車輛改裝與保鮮技術發展等合作對於促進兩岸業 者交流、台灣商品推廣、試點合作、深化與經驗 交流，都有助於推動兩岸冷鏈物流產業邁向更深 層次的合作階段。兩岸共同突破貿易與物流瓶頸, 將有利於加速台灣農特產品行銷大陸機會。

\section{5. 結論與建議}

\section{1. 結論}

台灣冷鏈物流的優勢在於長期引進了美國與日本的 先進冷鏈物流知識與經驗, 在經過多年的改進, 成為台 灣本土化的技術, 目前台灣現代化冷鏈管理毫不遜色於 美國、日本等國家。冷鏈倉庫的基礎設施包括地坪處理、 保溫材料、製冷機等, 都有非常豐富的經驗。不僅在物 流設備, 引進歐、美、日先進的物流科技, 政府也大力 扶持冷鏈物流業以及提升設備商開發能力與技術。台灣 冷鏈物流系統設備廠商已具有非常高水準的技術與開發 能力了, 冷鏈物流軟體、保溫車體、自動倉庫、蓄冷設 備貨架、冷庫設計規劃的能力, 都具有非常優勢的能力 與經驗。

台灣的冷鏈物流產業經過多年的發展與整合, 專業 分工架構已成型且趨於完善, 從倉儲、配送、資訊服務、 設備研發、銷售通路等各業種、業態均表現亮眼，但成 長亦遭遇內需市場規模過小等瓶頸。因此, 唯有透過資 本、人才、技術等資源的整合，方能促進冷鏈物流服務 的質變與進化, 加速台灣物流經驗與知識的經濟化和資 本化。

為配合國際發展趨勢與兩岸市場需求, 落實產業結 構優化轉型, 掌握發展契機, 台灣政府未來應朝製造業 服務化、服務業科技化與國際化、傳產業特色化之產業 策略來發展, 其中在服務業科技化與國際化方面, 將可 帶動物流產業服務科技化為主軸, 發展科技與管理應用 性高的冷鏈產業, 並透過導入全新科技能量, 以降低交 易成本，並提供更多的服務數量、更好的消費環境與服 務品質。並以台灣成熟的科技與管理優勢, 促進MIT低溫 商品便捷、優質的流通, 以兩岸冷鏈為起點, 進而扶植 台灣冷鏈相關業者建立差異化優勢, 以合作淬煉出國際 物流規模化服務品牌, 進軍國際市場。

\section{2. 建議}

台灣的冷鏈物流優勢在於, 有非常好的管理能力與 實踐能力, 整體冷鏈物流在嚴格規範安全品質及低成本 之運作之下, 又能符合社會大眾的需求。劣勢是, 台灣 市場太小。機會是, 大陸市場繁榮、興盛及崛起的東南 亞國家市場。威脅是, 培育國際人才不易與缺乏國際觀 
的市場布局。為了有效規劃兩岸產業佈局, 建議政府應 儘快設立兩岸產業策略小組, 作為與大陸中央與地方的 對應機構, 並增加技術研發與產業佈局之經費, 容許政 府經費研發成果移轉技術予合資公司及台商經營之地方 性物流中心。同時, 積極行銷台灣特色品與ECFA台灣產 品, 以國內優質的物流服務作為後盾, 建立我方產品進 入大陸市場的一套完善集運網絡。

為了有效規劃兩岸產業佈局, 建議政府應儘快設立 兩岸產業策略小組, 作為與大陸中央與地方的對應機構, 並增加技術研發與產業佈局之經費, 以研發成果移轉技 術予合資公司及台商經營之地方性物流中心。同時, 積 極行銷台灣特色品與ECFA台灣產品, 以國內優質的物流 服務作為後盾, 建立我方產品進入大陸市場的一套完善 集運網絡。

在市場方面仍應以中國大陸作為主要目標市場, 除 了其替換潛在市場龐大具吸引力外, 兩岸在冷鏈議題的 合作也有助台灣廠商進軍中國大陸，2010年兩岸四次產 業試點交流會議, 兩岸政府已宣布將『冷鏈物流』納為 主要合作試點項目之一, 並成立『兩岸產業布局策略小 組』協助推動, 初步建議以天津、廈門兩城市作為優先 試點示範城市。台灣冷鏈相關廠商若能整合成功推出完 整解決方案, 冷鏈物流將會是台灣廠商進軍中國大陸物 聯網應用的近程戰略目標。

\section{参考文献}

[1] 台灣行政院, 台灣產業結構優化一三業四化行動計畫, 2012。

[2] 台 灣 行 政 院 國 家 發 展 委 員 會 http: //www. ndc. gov. tw/cp. aspx?n=7F220D7E656BE749\&s $=5 \mathrm{C} 3 \mathrm{~F} 3 \mathrm{ED} 6 \mathrm{E} 0$.

［3］台灣行政院經濟部, 產業結構優化一三業四化論壇一服務 業科技化 (以低溫物流為例), 經濟部, 2012。

［4］台灣行政院衛生署，低溫食品物流管制作業指引。

[5] 台灣經濟研究院

http://tie. tier. org. tw/db/article/list. asp?code=IN D30-12\&ind_type=midind.

[6]台灣行政院經濟部工業局 R-net 冷媒資訊站, http://mail. en.wfc. edu. tw/, 2006/08/10.

[7] 陳慧娟, 台灣低溫產業的供應鏈整合, 物流技術與戰略, 六月 2008, 36-40。

８］陳慧娟, 國際冷鍕產業的推動趨勢, 物流戰略與技術, 四 月 $2009,15-21$ 。
［9］陳慧娟，國際冷鏈物流規範及技術發展趨勢。

[10] Cool Chain Quality Indicator (CCQI) CCQI Master Table, 2005 Cool Chain Association, Cool Chain Quality Indicator Standard.

[11] Perishable and Pharmaceutical Global Market Developments, for Cool Chain Association, Vatry, May 2007.

[12] Cold Chain Logistics, Shanghai Daily, July 2006.

[13] Ferdian. A Comparison of Event-driven Process Chains and UML Activity Diagram for Denoting Business Process. 2001.

[14] Global Cold Chain Regulations Influencing Storage, Handling, and Distribution of Clinical.

[15] Bruckner S, Albrecht A, Petersen B, and Kreyenschmidt J. "A predictive shelf life model as a tool for the improvement of quality management in pork and poultry chains." Food Control. 29 (2012) : 1-10.

\section{作者简介}

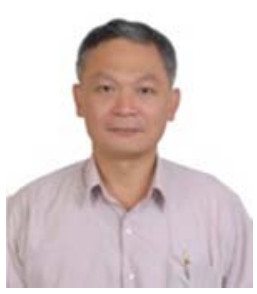

王天津, 男, 博士 (UWS, UK), 高雄 應用科技大學教授，管理學院院 長, 中國科學技術大學管理學院客 座教授（合肥）。創新四種方法：

Fuzzy Linguistic Preference Relations (Fuzzy LinPreRa) 、 Fuzzy VIKOR 、 Fuzzy PROMETHEE 、 Fuzzy Incomplete Linguistic Preference Relations(Fuzzy InLinPreRa)。期刊審稿： Information Sciences 、 European Journal of Operational Research 、 IEEE Transactions on Fuzzy Systems、Applied Soft Computing、Applied Mathematical Modelling。

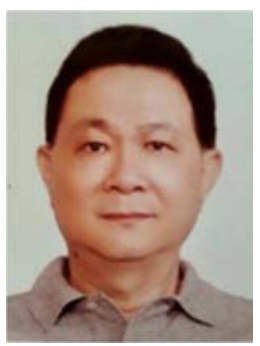

何基發, 男, 高雄應用科技大學碩士 生，下列公司董事長：伯宇海洋企業有 限公司、仲宇海洋企業有限公司、長盛 有限公司。 